\title{
The Cost-Effectiveness of Continuous Erythropoiesis Receptor Activator Once Monthly versus Epoetin Thrice Weekly for Anaemia Management in Chronic Haemodialysis Patients
}

\author{
Omar Maoujoud, ${ }^{1,2}$ Samir Ahid, ${ }^{1}$ Hocein Dkhissi, ${ }^{3}$ Zouhair Oualim, ${ }^{4}$ and Yahia Cherrah ${ }^{1}$ \\ ${ }^{1}$ Research Team of Pharmacoepidemiology \& Pharmacoeconomics, Medical and Pharmacy School, \\ Mohammed V University, Madinat Al Irfane, 10000 Rabat, Morocco \\ ${ }^{2}$ Department of Nephrology \& Dialysis, Military Hospital Agadir, 20450 Agadir, Morocco \\ ${ }^{3}$ Meknes Dialysis Center (on Behalf of Moroccan Society of Nephrology), 33150 Meknes, Morocco \\ ${ }^{4}$ IdrissAlakbar Dialysis Center (on Behalf of the Scientific Committee, Moroccan Society of Nephrology), 12470 Rabat, Morocco
}

Correspondence should be addressed to Omar Maoujoud; maoujoud@gmail.com

Received 2 October 2015; Accepted 6 December 2015

Academic Editor: Eitan Fibach

Copyright (C) 2015 Omar Maoujoud et al. This is an open access article distributed under the Creative Commons Attribution License, which permits unrestricted use, distribution, and reproduction in any medium, provided the original work is properly cited.

\begin{abstract}
Introduction. The aim of this study was to compare the cost-effectiveness of continuous erythropoietin receptor activator (CERA) once monthly to epoetin beta (EpoB) thrice weekly to maintain haemoglobin (Hb) within the range 10.5-12 g/dL. Methods. Prospective cohort study and cost-effectiveness analysis. Chronic haemodialysis patients (CHP), being treated with EpoB, were selected for two periods of follow-up: period 1, maintaining prior treatment with EpoB, and period 2, conversion to CERA once monthly. $\mathrm{Hb}$ concentrations and costs were measured monthly. Health care payer perspective for one year was adopted. Results. $75 \mathrm{CHP}$ completed the study, with a mean age of $52.9 \pm 14.3$ years. Baseline $\mathrm{Hb}$ was $11.14 \pm 1.18 \mathrm{~g} / \mathrm{dL}$ in EpoB phase and $11.46 \pm 0.79 \mathrm{~g} / \mathrm{dL}$ in CERA phase; we observed a significant increase in the proportion of patients successfully treated (Hb within the recommended range), $65.3 \%$ versus $70.7 \%$, p: 0.008 , and in the average effectiveness by $4 \%$ ( 0.55 versus 0.59$)$. Average cost-effectiveness ratios were 6013.86 and 5173.64\$, with an ICER CERA to EpoB at -6457.5 . Conclusion. Our health economic evaluation of ESA use in haemodialysis patients suggests that the use of CERA is cost-effective compared with EpoB.
\end{abstract}

\section{Introduction}

The incidence and prevalence of patients with chronic kidney disease (CKD) are growing worldwide [1,2]. In patients with $\mathrm{CKD}$, the kidneys are unable to produce enough erythropoietin to stimulate adequate production of red blood cells, causing renal anaemia [3,4]; in addition, this anaemia is associated with reduced quality of life, high morbidity, and mortality in chronic haemodialysis patients (CHP) $[5,6]$; it is commonly managed using erythropoiesis stimulating agents (ESA) [7-9]. The class of ESA includes epoetin alpha, epoetin beta (EpoB), darbepoetin, and the pegylated erythropoietin continuous erythropoiesis receptor activator (CERA) [10-12]. ESA such as epoetin alfa and EpoB require frequent administration (from three times weekly to once weekly) [13], while darbepoetin alfa can be administered once weekly or once every 2 weeks, to maintain stable $\mathrm{Hb}$ levels within the desired target range [14]. CERA has been recently introduced in the Moroccan market to provide correction of renal anaemia, which has unique pharmacologic properties, acting differently than short-acting EpoB at the erythropoietin receptor level [15], with a long serum half-life, allowing for once-amonth dosing. Several studies have suggested that CHP can be readily switched from short-acting ESA to CERA, but the health outcomes for patients and the effects on cost have not been extensively investigated.

The purpose of this study was to carry out a costeffectiveness analysis (CEA) to evaluate the impact of switching patients from their current short-acting ESA therapy to CERA once monthly in a real-world setting, in this order; 
we conducted a multicenter prospective observational study, to compare the cost-effectiveness of CERA once monthly to treatment with EpoB thrice weekly in Moroccan haemodialysis patients.

\section{Patients and Methods}

Patients were screened at 3 haemodialysis centers in Morocco from January to December 2013; all participating centers used EpoB (Recormon; Hoffmann-La Roche Ltd., Basel, Switzerland) thrice weekly to treat their ESRD patients who had renal anaemia. To be included in the study, CHP were required to meet the following criteria: adult patients ( $\geq 18$ years of age) with chronic renal anaemia, on chronic haemodialysis therapy with the same mode of dialysis for at least 12 weeks before, $K t / V \geq 1.2$, baseline $\mathrm{Hb}$ concentration between 10.5 and $12 \mathrm{~g} / \mathrm{dL}$; stable baseline $\mathrm{Hb}$ concentration, continuous subcutaneous maintenance EpoB therapy with the same dosing interval for at least 8 weeks (no change of the weekly dosage), adequate iron status defined as serum ferritin $\geq 200 \mathrm{ng} / \mathrm{mL}$, or transferrin saturation $\geq 20 \%$. Patients were excluded from the study when they had received an organ transplant, chemotherapy, or surgery, because they may have become anaemic for reasons other than CKD.

2.1. Study Design. The conversion from EpoB to CERA (methoxy polyethylene glycol-epoetin beta; Mircera; Hoffmann-La Roche Ltd., Basel, Switzerland) once monthly was already decided by the health care payer policy, who is the provider of erythropoietin stimulating agents for all patients, and was planned after a period of 6 months. Both EpoB and CERA have already been approved for renal anaemia in CHP and got the market authorization. Selected patients were not required to undergo any additional medical interventions, tests, or procedures, as they were receiving usual dialysis care and treated for renal anaemia following national and international guidelines. CHP that complied with the inclusion criteria were selected for a follow-up over two periods: the first period during six months (months -6 to 0 ), maintaining prior treatment with EpoB thrice weekly, and the second for six months (months 0 to 6 ), after changing treatment to CERA once monthly.

2.2. Anaemia Treatment Protocol. All enrolled patients received EpoB or CERA subcutaneously at the end of the dialysis session. The frequency of administration was 3 times a week for EpoB, and every four weeks for CERA, EpoB dosages were adjusted to maintain $\mathrm{Hb}$ within the recommended range $10.5-12 \mathrm{~g} / \mathrm{dL}$, at intervals of 1 to 2 weeks. Dosages were decreased by $25 \%$ for $\mathrm{Hb}$ increases $>1 \mathrm{~g} / \mathrm{dL} /$ month, versus previous level, and increased by $25 \%$ for $\mathrm{Hb}$ decreases $>1 \mathrm{~g} / \mathrm{dL} / \mathrm{month}$. The starting dose of CERA was based on the previous weekly dose of EpoB in the week before conversion. For patients who previously received $<8000 \mathrm{UI}$ of EpoB per week; the starting dose of CERA was $120 \mu \mathrm{g}, 200 \mu \mathrm{g}$ when previous weekly EpoB was in the range 8000-16 000 IU, and $360 \mu \mathrm{g}$ when previous weekly EpoB was >16000 IU. Doses for all patients were to be adjusted so that haemoglobin concentrations would remain within a target range of 10.5$12 \mathrm{~g} / \mathrm{dL}$. During the follow-up, CERA dosages were decreased by $25 \%$ for $\mathrm{Hb}$ increases $>1 \mathrm{~g} / \mathrm{dL} /$ month, versus previous level, and increased by $25 \%$ for $\mathrm{Hb}$ decreases $>1 \mathrm{~g} / \mathrm{dL} / \mathrm{month}$, according to protocol and not more often than once monthly. Iron supplementation (iron sucrose) was to be initiated or intensified according to centre practice in cases of iron deficiency (serum ferritin $<100 \mu \mathrm{g} / \mathrm{L}$ or transferrin saturation $<20 \%$ ) and discontinued in patients who had serum ferritin levels $>800 \mu \mathrm{g} / \mathrm{L}$ or transferring saturation $>50 \%$.

2.3. Dialysis Protocol. All patients were on haemodialysis therapy using the AK 200 ULTRA-S dialysis machine (Gambro AB, Lund, Sweden). Ultrapure water was used for preparation of dialysis fluid and bicarbonate was provided from powder cartridges. Treatment time ranged from $4 \mathrm{~h}$ to $5 \mathrm{~h}$ per session, three times a week, with high-flux synthetic dialyser (UF-coefficient $>20 \mathrm{~mL} / \mathrm{mmHg} / \mathrm{h}$, surface area 1.4 to $2.1 \mathrm{~m}^{2}$ ). Anticoagulation was performed with low molecular weight heparin and consisted of a single dose of of 3000 to 4000 units of enoxaparin. The ultrafiltration rate was programmed to reach the patient's optimal dry weight and ranged from $500 \mathrm{~mL} / \mathrm{h}$ to $900 \mathrm{~mL} / \mathrm{h}$. Water treatment system consisted of double reverse osmosis, classic pretreatment (softener, activated carbon, and microfiltration), distribution loop with permanent water circulation, and direct delivery to dialysis machines.

2.4. Assessments. Based on Nephrology Moroccan clinical practice guidelines [16], it is assumed that CHP treated with EpoB or CERA are monitored every 4 weeks, and the following laboratory parameters were gathered at baseline and then monthly until the end of the study: $\mathrm{Hb}$, white blood cell (WBC) count, red blood cell (RBC) count, hematocrit (Hct), and platelet count, iron storage status: serum iron, and transferrin saturation (TSAT), ferritin, and biochemical profile: serum intact parathyroid hormone (iPTH), C-reactive protein (CRP), protein, albumin, total cholesterol, triglyceride, uric acid, high-density lipoprotein (HDL), low-density lipoprotein (LDL), glucose, blood urea nitrogen (BUN), creatinine $(\mathrm{Cr})$, sodium $(\mathrm{Na})$, potassium $(\mathrm{K})$, calcium $(\mathrm{Ca})$, and phosphate $(\mathrm{P})$.

2.5. Cost-Effectiveness Analysis. The cost-effectiveness analysis (CEA) was conducted from the healthcare payer perspective, and we applied decision analytic techniques to evaluate the average and incremental cost-effectiveness of EpoB and CERA in the treatment of anaemia. Key model inputs included clinically relevant effectiveness measures, which was measured by the clinical success rate of treatment (CSR), defined as the proportion of patients successfully achieving the $\mathrm{Hb}$ target as well as drug acquisition costs for both treatments considered. Model outputs were expected cost-effectiveness ratio and the incremental cost-effectiveness ratio (ICER) that represents the additional cost and effectiveness obtained, when CERA regime is compared to the EpoB regime. In this order, we considered the effectiveness and cost in terms of $\mathrm{Hb}$ level achieved during the two periods of six months of follow-up. Two $\mathrm{Hb}$ ranges were considered: 10,5 
to $12 \mathrm{~g} / \mathrm{dL}$ (the recommended range), higher than $12 \mathrm{~g} / \mathrm{dL}$ or lower than 10,5 $\mathrm{g} / \mathrm{dL}$. Measurements of $\mathrm{Hb}$ were performed every 4 weeks during the study period; the mean of six consecutive measures at each phase of the study was used to categorize patients on the two groups considering $\mathrm{Hb}$ ranges. In our analysis, the CSR was calculated at two time periods: (1) from month -6 to month 0 for EpoB and (2) from month 0 to month 6 for CERA. Costs were calculated for each patient in the 2 periods of the study, based on 24-week drug acquisition costs, and these patient-specific costs were averaged across patients within the same range of $\mathrm{Hb}$.

The cost-effectiveness ratio was expressed as the mean 1year drug costs per one per cent of EPoB or CERA patients successfully treated during the defined time period:

Average cost-effectiveness ratio of treatment

$$
=\frac{\text { Average Cost of treatment }}{\text { Average Effectiveness treatment }} \text {. }
$$

The average cost-effectiveness ratio was then compared between EpoB and CERA.

The ICER was defined as the difference in mean 1-year cost between EpoB and CERA divided by the difference in average effectiveness between the two treatments:

$$
\begin{aligned}
& \text { ICER (Cera versus EpoB) } \\
& =\frac{\text { COST Cera }- \text { COST EpoB }}{\text { EFFECTIVENESS Cera }- \text { EFFECTIVENESS EpoB }} .
\end{aligned}
$$

2.6. Perspective, Timeframe, and Source of Cost Data. A health care payer perspective was adopted, for a time horizon of one year. We considered real market costs approved by the Moroccan Agency on Medical Insurance (ANAM). All costs were collected every 3 months, reported in Moroccan dirhams (MAD), then converted to US Dollar (\$) (1 US Dollar $=9,297 \mathrm{MAD}$ ), and were inflated to 2013 costs using the consumer price index for health care goods in Morocco. A discount rate of $3 \%$ was applied to both costs and utilities. All analyses were performed using TreeAge Pro 2015 (TreeAge Software, Williamstown, MA).

2.7. Assumptions. It was assumed that there is no change in hospitalization attributable to both treatments, that patients make no extra doctor visits due to CERA or EpoB, as they visit the hospital for dialysis irrespective of the treatment regimen for anaemia, and that surveillance costs are assumed to be the same for both treatments.

2.8. Sensitivity Analysis and Monte Carlo Simulation. Oneway and two-way sensitivity analyses were performed by varying baseline estimates for costs, effectiveness within a range of potentially reasonable values, and evaluating whether these changes modify the conclusions reached. Probabilistic sensitivity analysis was performed using Monte Carlo simulation (MCS) to explore overall uncertainty in the model, by creating 50,000 samples, for which expected values were calculated. Normal distributions were used for relative and baseline risks. Log-normal distributions were applied to the costing estimates.

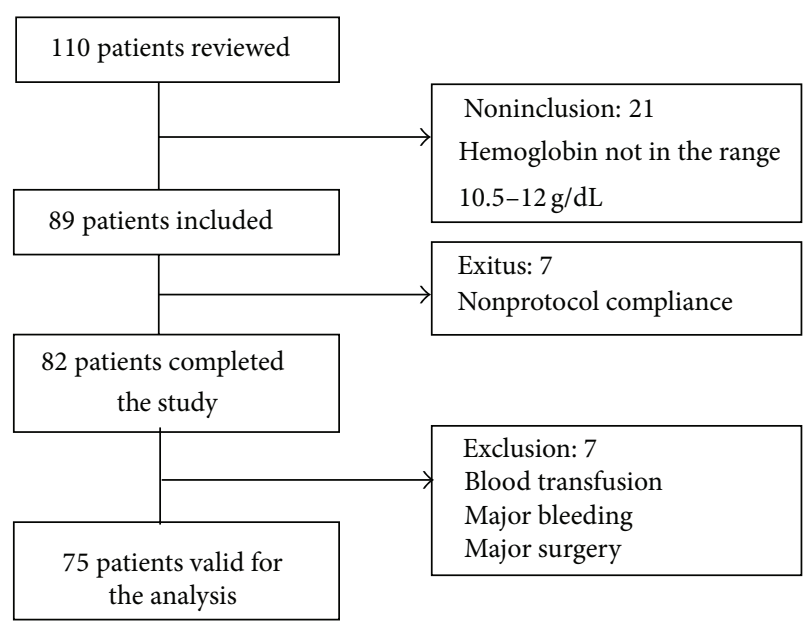

Figure 1: Patients included in the study.

2.9. Statistical Analysis. Results are expressed as percentages for discrete variables, medians, and interquartile ranges for nonnormally distributed continuous variables, and mean \pm standard deviation for normally distributed continuous variables. All statistical analyses were performed using the statistical package for social sciences (SPSS) software 17.0 (SPSS, Chicago, IL, USA), and comparisons of groups were performed by Mann-Whitney or Wilcoxon test depending on the variable distributions. The study was powered to detect an incremental cost-effectiveness ratio between CERA and EpoB of less than a nominated critical threshold of three times 2013 Moroccan per capita gross domestic product. As almost all developing countries, there is no incremental costeffectiveness threshold in Morocco, being considered as ideal for the acceptance of a given health intervention. So, we used the value established by the World Health Organization's Commission on Macroeconomics and Health, corresponding to three times the per capita gross domestic product (GDP), as a threshold for cost-effectiveness. According to the World Bank, the 2013 per capita GDP value was 3092\$. For this reason, if a health procedure presents an ICER lower than $9186 \$$ in Morocco, it may be considered as being cost-effective. Therefore, it was calculated that a total sample size of 70 would be sufficient to detect a $15 \%$ decrease in average costeffectiveness ratio associated with CERA in comparison to EpoB with $80 \%$ power at $p: 0.05$.

\section{Results}

3.1. Patient Cohort Characteristics. We screened a total of 110 patients; 89 of them complied with the inclusion criteria (Figure 1); screen failures were due to an $\mathrm{Hb}$ not in the recommended range. In total, 82 patients have completed the study and 75 were valid for the analysis (48 (64.9\%) men and 27 (35.1\%) women), with a mean age of a mean age of $52.9 \pm 14.3$ years; the most common reasons for exclusion were active bleeding (major trauma, gastric ulcer bleeding, or surgery). Table 1 summarizes demographic and baseline characteristics of valid patients, diabetic nephropathy was 
TABLE 1: Baseline demographic and clinical characteristics of the haemodialysis population.

\begin{tabular}{lc}
\hline Parameters & \\
\hline Patients $(n)$ & 75 \\
Age (years) & $56.6 \pm 11.77$ \\
Male (\%) & $48(64.9 \%)$ \\
Primary renal disease $n(\%)$ & \\
$\quad$ Diabetes & $22(28.2)$ \\
$\quad$ Glomerulonephritis & $10(12.8)$ \\
$\quad$ Unknown & $24(30.7)$ \\
$\quad$ Vascular & $12(15.3)$ \\
$\quad$ Others & $10(12.8)$ \\
Vascular access $n$ (\%) & \\
$\quad$ Fisulta & $70(93)$ \\
Catheter & $5(7)$ \\
Viral hepatitis B or C $n(\%)$ & 0 \\
Patients on antihypertensive therapy $n(\%)$ & $35(46.66)$ \\
Statins $n$ (\%) & $31(41.33)$ \\
Time on dialysis (months) & $75.2 \pm 25.6$ \\
Predialysis systolic BP (mmHg) & $138 \pm 21.6$ \\
Predialysis diastolic BP (mmHg) & $81 \pm 2,6$ \\
Dry weight (kg) & $68.2 \pm 7.6$ \\
Haemoglobin (g/dL) & $10.91 \pm 1.56$ \\
Albumin (g/L) & $3.9 \pm 0.82$ \\
C-reactive protein (mg/L) & $5.25[1.9-11.6]$ \\
Ferritin (ng/mL) & $392.64 \pm 250$ \\
Transferrin saturation (\%) & $29.5 \pm 5.4$ \\
Kt/V & $1.25[1.06-1.57]$ \\
Dialysis session length & $243.7 \pm 15.6$ \\
Intact parathyroid hormone (pg/mL) & $362.7[170.9-521.2]$ \\
Calcium (mg/dL) & $9.39 \pm 0.71$ \\
Phosphate (mg/dL) & $4.33 \pm 1.83$ \\
Cholesterol (mg/dL) & $166.2 \pm 49.2$ \\
LDL & $94.34 \pm 33.2$ \\
Triglyceride (mg/dL) & $40.79 \pm 20.6$ \\
\hline & $130.5 \pm 23.6$ \\
\hline
\end{tabular}

the most common cause of renal disease (28.2\%), and $65.4 \%$ of the patients had a history of cardiovascular disease. Vascular access was an arteriovenous fistula in the majority of patients $70(93 \%)$, and 5 patients were treated via a permanent catheter.

3.2. Efficacy Evaluation. Baseline $\mathrm{Hb}$ level was $11.14 \pm$ $1.18 \mathrm{~g} / \mathrm{dL}$ in EpoB phase and $11.46 \pm 0.79 \mathrm{~g} / \mathrm{dL}$ in CERA phase; there was a nonsignificant increase in mean $\mathrm{Hb}$ level after conversion to CERA $(11.25 \pm 0.73$ versus $11.42 \pm 0.63 \mathrm{~g} / \mathrm{dL}$ $p$ : 0.08), but we observed a significant increase in the proportion of patients successfully treated (CSR 65.3\% versus $70.7 \%$ p: 0.008). Furthermore, the proportion of patients with $\mathrm{Hb}<10.5 \mathrm{~g} / \mathrm{dL}$ was $14 \%$ in EpoB phase and $7 \%$ in CERA phase, and the proportion of patients with $\mathrm{Hb}>12 \mathrm{~g} / \mathrm{dL}$ was $12 \%$ and $15 \%$, respectively, without need of blood transfusions during the two periods of follow-up. The average effectiveness

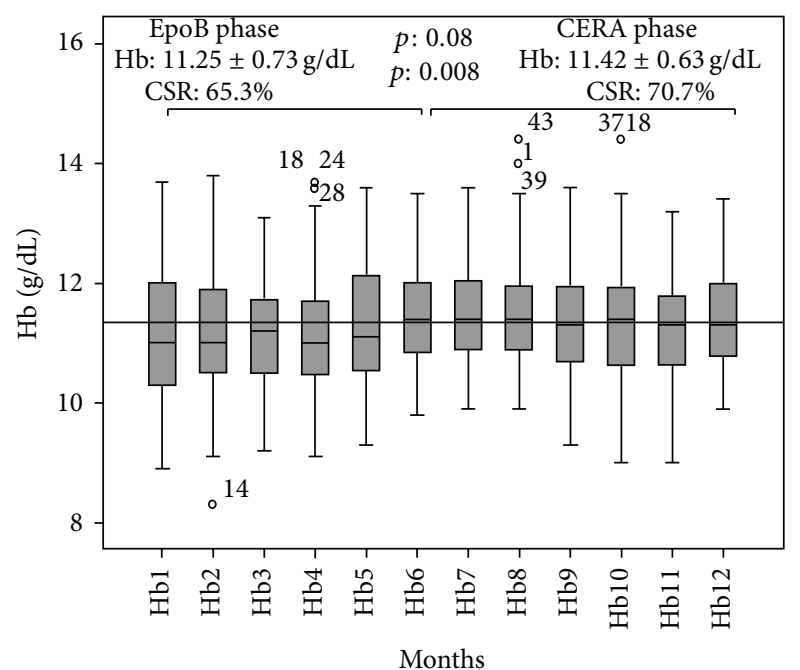

FIGURE 2: Evolution of mean $\mathrm{Hb}$ concentration during the two phases of the study. Hb: hemoglobin, EpoB recombinant human erythropoietin beta, CERA: continuous erythropoietin receptor activator, and CSR: clinical success rate (HB within the target 10,5$12 \mathrm{~g} / \mathrm{dL})$.

rose by $4 \%$ ( 0.55 versus 0.59 ). Monthly evolution of $\mathrm{Hb}$ during the two phases of the study is reported in Figure 2.

3.3. EPO and Iron Requirements. The mean weekly dose during the EpoB period was $6104 \pm 3178$ ui and was $106.4 \pm$ $50.1 \mu \mathrm{g} / \mathrm{month}$ in the CERA phase; there was no significant difference in the proportions of patients receiving IV iron during the two periods of follow-up (87.5\% and $89.1 \%$, resp., p: 0.23 ), and conversion from EpoB to CERA did not result in statistically significant change in mean serum ferritin, TSAT, or iron dose as reported in Table 2. There were no significant differences between EpoB and CERA periods in terms of dialysis doses $(K t / v 1.26 \pm 0.4$ versus $1.27 \pm 0.1, p: 0.1)$ and duration of HD sessions ( $244.5 \pm 12.4$ versus $243.5 \pm 11.4 \mathrm{mn}$, $p: 0.34)$, also there were no significant changes in inflammatory parameters: serum C-reactive protein $(3.3 \pm 1.1$ versus $3.7 \pm 0.9 \mathrm{mg} / \mathrm{L}, p: 0.11)$ and albumin levels $(3.8 \pm 1.8$ versus $4.1 \pm 0.7 \mathrm{~g} / \mathrm{L}, p: 0.21)$. Patients with permanent central venous catheter had a nonsignificant higher dose of ESA in comparison to patient with arteriovenous fistula (6107.5 ui versus 6101.2 ui, p: 0.1$)$ for EpoB and (110.4 versus 102.5, p: 0.2$)$ for CERA.

3.4. Cost Effectiveness Analysis. Decision tree framework is presented in Figure 3(a), with CERA and EpoB branches, and the rolled back model with calculations is presented in Figure 3(b). Costs, effectiveness, and incremental associated with CERA administration to CHP, compared to EpoB, are summarized in Table 3. Based on 6-month drug acquisition cost, the mean per patient cost was $1644.2 \pm 859.4 \$$ for EpoB and $1515.5 \pm 713 \$$ for CERA, projected annual per patient costs were $3288.49 \pm 1718.9 \$$ and $3030.19 \pm 1426 \$$, respectively, with a cost saving associated with CERA at $-258.3 \$$. Average annual effectiveness estimated by the model was 0.55 for 


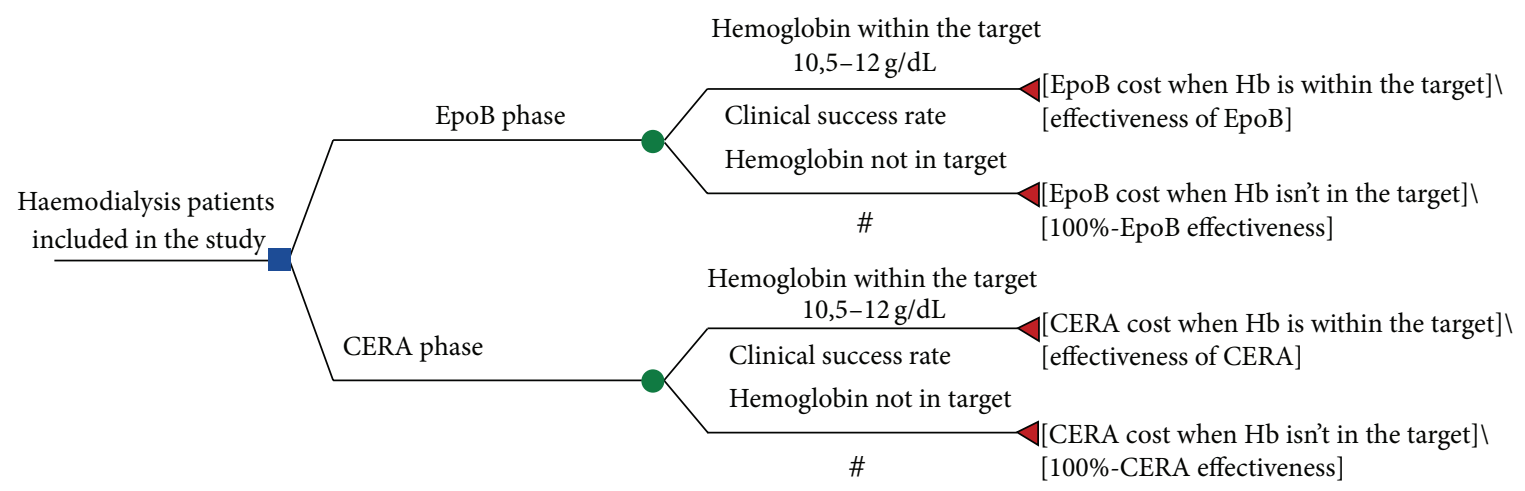

(a)

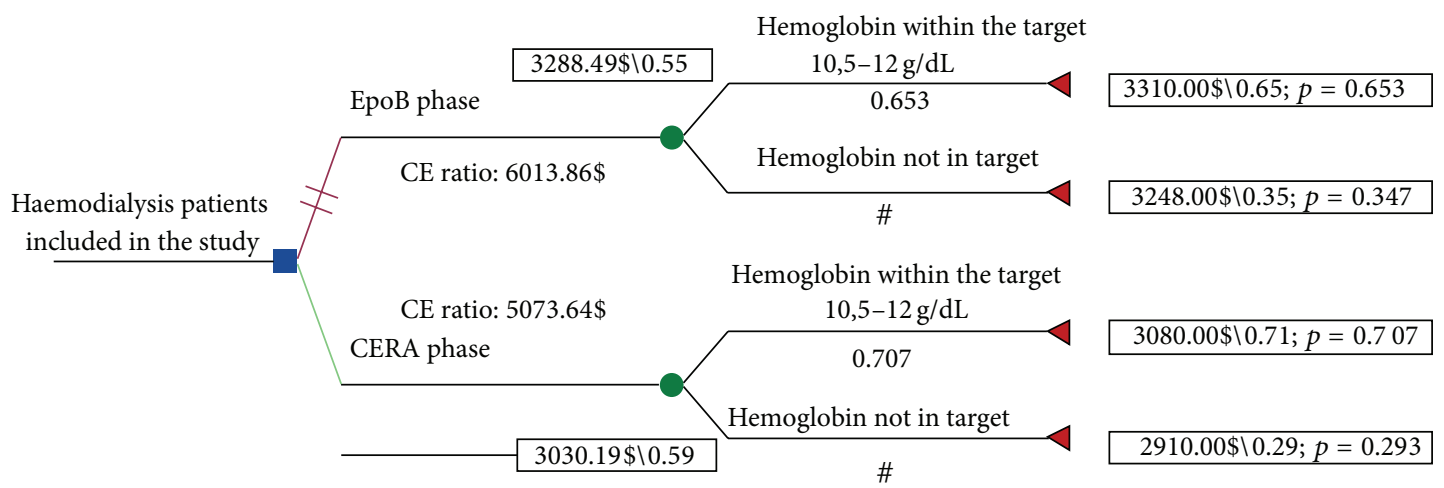

(b)

FIGURE 3: (a) Decision tree framework. (b) Results of cost-effectiveness analysis after roll-back calculation. EpoB: recombinant human erythropoietin beta, CERA: continuous erythropoietin receptor activator, CE ration: cost-effectiveness ratio.

TABle 2: Anaemia management during the study.

\begin{tabular}{lccc}
\hline Parameters & EpoB phase & CERA phase & $p$ \\
\hline$n$ & 75 & 75 & \\
\hline Hemoglobin g/dL & $11.25 \pm 0.73$ & $11.42 \pm 0.63$ & 0.08 \\
\hline $\begin{array}{l}\text { Transferrin } \\
\text { saturation \% }\end{array}$ & 28.4 & 29.2 & 0.35 \\
\hline $\begin{array}{l}\text { Ferritin } \mathrm{ng} / \mathrm{mL} \\
\text { IV iron \% }\end{array}$ & 288.5 & 299.3 & 0.2 \\
$\begin{array}{l}\text { IV iron dosage } \\
\text { mg/month }\end{array}$ & 87.5 & 89.1 & 0.23 \\
\hline ESA dose & $6104 \pm 3178$ ui & $106.4 \pm 50.1 \mu \mathrm{g}$ & \\
\hline CSR $n \%$ & $49(65.3)$ & $53(70.7)$ & 0.008 \\
\hline $\begin{array}{l}\text { Hb }>12 \mathrm{~g} / \mathrm{dL} \\
n(\%)\end{array}$ & $12(16)$ & $15(20)$ & 0.001 \\
\hline $\begin{array}{l}\mathrm{Hb}<10.5 \mathrm{~g} / \mathrm{dL} \\
n(\%)\end{array}$ & $14(18.7)$ & $7(9.3)$ & 0.001 \\
\hline
\end{tabular}

CSR: clinical success rate $\mathrm{Hb}$ within the range $10.5-12 \mathrm{~g} / \mathrm{dL}$.

ESA: erythropoietin stimulating agent.

$\mathrm{Hb}$ : haemoglobin.

EpoB: epoetin beta.

CERA: continuous erythropoietin receptor activator.

EpoB and 0.59 for CERA, and average cost-effectiveness ratios were $6013.86 \$$ and $5173.64 \$$, respectively, with an ICER at $-6457.5 \$$ per one per cent of patients successfully treated, so the treatment with EpoB was dominated by CERA as shown in the cost-effectiveness diagram Figure 4.

3.5. Sensitivity Analyses and Monte Carlo Simulation. We performed one-way and multiway sensitivity analysis, the ICERs did not change significantly, despite application of variation rates of $\pm 10 \%$ in each of the parameters of cost and effectiveness individually, and clinically implausible changes in variables were required to significantly improve the cost effectiveness EpoB in comparison to CERA. The results of probabilistic sensitivity analysis by Monte Carlo simulation based on 50000 random iterations are shown in Figure 5. The scatterplot illustrates the robustness of the model. Analysis of the results shows that $100 \%$ of the points are in the lower right hand portion of the graph (best effectiveness and lower cost), demonstrating that CERA remained more effective, less costly, and hence the dominant treatment compared to EpoB. Also, the robustness of the calculated ICER was confirmed by MCS as shown in Figure 6.

\section{Discussion}

The present study found that CERA is more cost-effective than EpoB, making it the dominant treatment for the management of anaemia in chronic haemodialysis patients. To our knowledge, this work is the first to evaluate the costeffectiveness of CERA prospectively in a real-life practice. 
TABLE 3: Cost-effectiveness analysis of the study.

\begin{tabular}{lcc}
\hline Parameters & EpoB & CERA \\
\hline$N$ & 75 & 75 \\
Patients successfully treated $n$ (\%) & $49(65.3)$ & $53(70.7)$ \\
Hb 10.5-12 g/dL & $26(34.7)$ & $22(29.3)$ \\
Patients not successfully treated $n$ (\%) & & 0.008 \\
$\mathrm{Hb}>12$ or $\mathrm{Hb}<10.5 \mathrm{~g} / \mathrm{dL}$ & $1644.2 \pm 859.4$ & $1515.5 \pm 713$ \\
Drug costs \$ & 3288.49 & 3030.19 \\
$\quad$ Mean 6-month drug cost per patient & - & -258.3 \\
$\quad$ Mean 1-year drug cost per patient & 0.55 & 0.59 \\
Incremental 1-year cost Cera versus EpoB \$ & - & 0.03 \\
Average effectiveness & & 0.03 \\
Incremental effectiveness Cera versus EpoB \$ & 6013.86 & 5173.64 \\
Average cost-effectiveness ratio & & -6457.5 \\
\$/per one per cent of patients successfully treated & & \\
ICER Cera versus EpoB & & \\
\$/per one per cent of patients successfully treated & & \\
\hline
\end{tabular}

ESA: erythropoietin stimulating agent.

Hb: haemoglobin.

EpoB: epoetin beta.

CERA: continuous erythropoietin receptor activator.

ICER: incremental cost-effectiveness ratio.

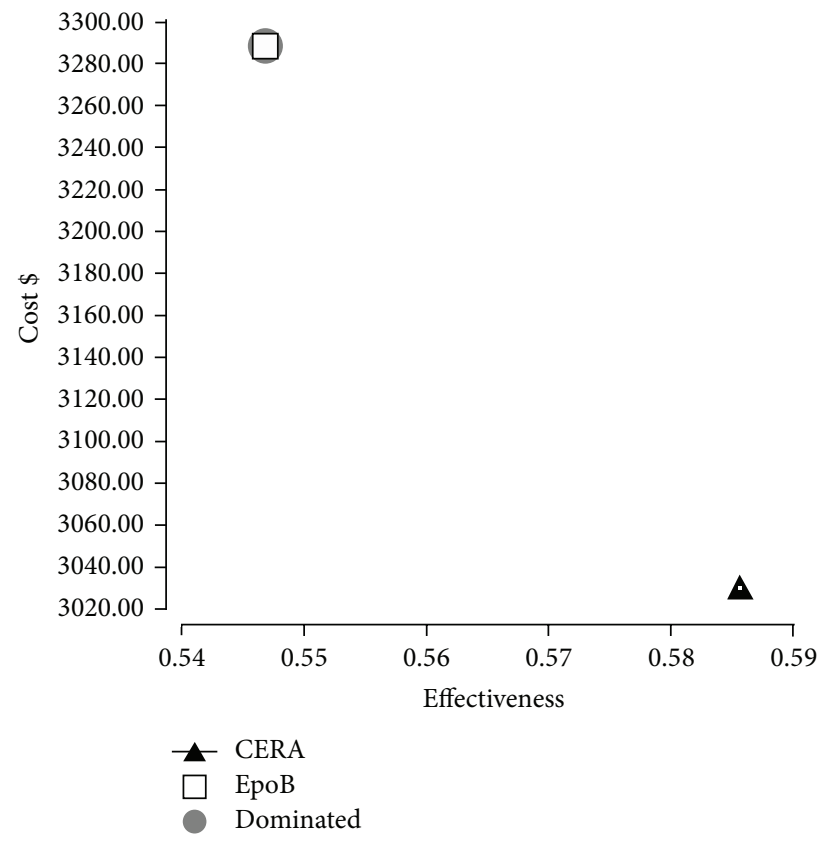

FIGURE 4: Cost-effectiveness diagram. EpoB is dominated by CERA since it is more costly and less effective.

As demonstrated in the recent review published by Schmid [14], the literature query of studies dealing with the cost or the cost-effectiveness of CERA was poor; only 18 publications were included in his analysis, most of the available data was from meeting abstracts (eleven), and only seven published studies were in peer-reviewed journals. Majority of included studies were retrospectives, and reported data were only about cost of therapy after a switch to CERA from

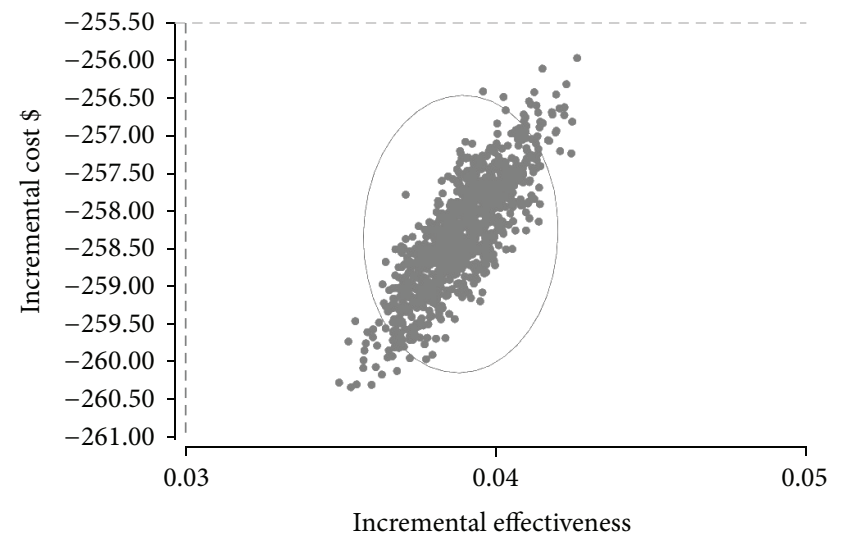

Figure 5: Results of Monte Carlo simulation of incremental cost and effectiveness scatter plot of CERA versus EpoB, based on 50000 random iterations of cost-effectiveness model.

single-center experiences. Gonzalez et al. [17] reported in a meeting abstract a CEA of CERA compared to erythropoietin alpha, on the base of a decision tree model that simulated the treatment costs and outcomes in Mexican haemodialysis patients. In this study, the clinical success rate (patients within $11-12.5 \mathrm{Hb} / \mathrm{dL}$ levels) when using CERA versus EPO-alpha showed significant difference $(86.79 \%$ versus $50.48 \%$ resp., $p<0.0001)$, treatment care cost per year for CERA was $\$ 2,776.13$ versus $\$ 2,907.88$ for erythropoietin alpha $(p<$ 0.0001 ), and the cost-effectiveness plane indicates that CERA is a highly cost-effective therapy, with a probability of 0.60 to be cost saving and 0.99 of probability of being cost effective. In another study published as an abstract, aimed to determine the cost-effectiveness of anaemia treatment in dialysis patients for Brazilian Public Health System [18], using 


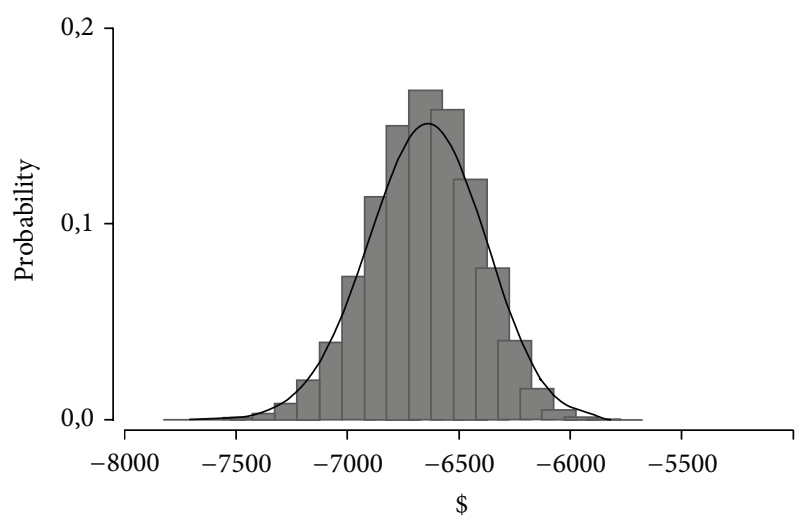

FIgURE 6: Probabilistic sensitivity analysis of ICER distribution of CERA versus EpoB. The analysis confirmed the robustness of the model, based on 50000 random iteration; the ICER remain within the range of calculated ICER $\pm 10 \%$.

a Markov model of a hypothetical cohort of dialysis patients treated with CERA or epoetin for four years, the model showed that epoetin treatment was more cost-effective than CERA treatment. Unfortunately, it was not possible to evaluate the methodology of both previous publications and there concordance with international guidelines for CEA studies [19]. Considering only the cost of treatment; 3 costminimisation studies reported as meeting abstracts confirm our finding of cost saving after switch to CERA from another short acting EPO; Bezditko et al. [20] estimated the cost reduction about $5-35 \%$, based on decision tree analysis. In his pharmacoeconomic evaluation of maintenance treatment of anaemia, in Ukrainians haemodialysis patients, the average costs of CERA treatment per patient on haemodialysis were $\$ 173 /$ week (intravenous route of administration) and $\$ 130 /$ week (subcutaneous route of administration) and average costs for using the shorter-acting EpoB drugs were \$267194/week and \$133-182/week, respectively. Franz et al. [21], in a Swiss multicenter prospective observational study, analysed data of dialysis patients treated with ESA over a period of 12 months. After the switch to CERA from treatment with either darbepoetin alfa or epoetin alfa/beta, the cost of ESA treatment decreased by $14 \%$ and patients maintained stable $\mathrm{Hb}$ values in the first 6 months after conversion. In contrast, Albero Molina et al. [22] reported a $+66.4 \%$ increasing cost after switch to CERA, in a 6-month prospective follow-up of 17 haemodialysis patients, with stable dose of subcutaneous EpoB average costs/patient/month: EpoB (£174.30 $£ £ 85.40)$ versus CERA ( $£ 290.10 \pm £ 69.00)$. In another Spanish study, Escudero-Vilaplana et al. [23] reported similar cost increase after switch to CERA from EpoB $£ 103.2$ versus $£ 147.5$. In our analysis, the cost reduction related to CERA can partially be explained by the lower doses required after conversion from EpoB. Initial dose was calculated according to manufacturer guidelines, and during the follow-up doses adjustments were permitted according to $\mathrm{Hb}$ evolution. We believe that this work is the first to report data related to CERA use in such North African ethnic population, similarly to our finding in another Mediterranean population, authors reported low dose requirement of CERA (mean monthly dose was
$112.4 \pm 76.78 \mu \mathrm{g}$ ) to maintain $\mathrm{Hb}$ in the range $10-12 \mathrm{~g} / \mathrm{dL}$ [24]. Also, low dose requirement in CERA phase can be explained by an increase in iron use in terms of proportion of patients receiving iron, serum ferritin, TSAT, and mean iron doses, but this improvement did not reach statistical significance in comparison to EpoB period. Of note, majority of available data suggests cost saving after conversion to CERA, rather than cost increase; it was difficult to have a conclusion from these previous studies. Since they were surrounded by considerable uncertainty and unavailable full-text articles, few abstracts reported information about baseline and evolution of $\mathrm{Hb}, \mathrm{ESA}$ doses, median cost/patient, and iron status, and majority of analyses were based on hypothetical cohorts rather than real-life follow-up. For this reasons, we have tried in our analysis to follow the guidelines of the International Society for Pharmacoeconomics and Outcomes Research (ISPOR), health economic evaluation publication guidelines, and Consolidated Health Economic Evaluation Reporting Standards (CHEERS) [19]. Results from a number of previous studies suggested that adoption of a once-monthly ESA could provide considerable time savings for dialysis centers [25-27], in our study; we did not consider healthcare personnel time associated with routine anaemia management tasks, since we adopted the health care payer perspective. However, our study has some limitations. First, the perspective was that of a health-care payer and not a societal one, and as such we did not include indirect costs such as loss of productivity and travel costs. The absence of evidence that ESA use increases employment rats in haemodialysis patients makes it unlikely that adopting societal perspective would have changed our results $[5,28,29]$. Secondly, we considered only drugs acquisition costs, without including other direct medical costs such hospitalization, medications, and consultations; however, previous research indicated that these additional cost components would be similar between CERA and EpoB [30]. In our CEA, we considered the effectiveness in terms of $\mathrm{Hb}$ target reached, rather than a hard end point like mortality or change in quality of life (QOL), the initial design of the study was not appropriate to evaluate the cost per quality adjusted life year (QALY), and the short duration of follow-up was not adequate to expect a significant change in QOL or in mortality related to conversion to CERA. For this reason, we adopted a valid surrogate marker such as the CSR, since a strong correlation between QOL and Hb levels in CHP is admitted now.

In summary, this medicoeconomic evaluation of ESA use in haemodialysis patients suggests that administering CERA once monthly is cost-effective when the health care perspective is employed. We performed our study in accordance with current anaemia management guidelines in haemodialysis patients, and following Health Economic Evaluation Reporting Standards. These data would assist health care decision makers and services reimbursement authorities as they aim to provide the most cost-effective treatments to patients.

\section{Ethical Approval}

All procedures performed in studies involving human participants were in accordance with the ethical standards of 
the institutional and/or national research committee and with the 1964 Helsinki Declaration and its later amendments or comparable ethical standards. The study was performed with informed consent, and following all guidelines for experimental investigations, required by the Institutional Review Board of which all authors are affiliated to.

\section{Consent}

Informed consent was obtained from all individual participants included in the study.

\section{Disclosure}

Partial data on this paper has been presented as a poster at the World Congress of Nephrology, Organized by the International Society of Nephrology: Cape Town, South Africa, March 2015, Poster no. SAT-451.

\section{Conflict of Interests}

The authors declare that they have no conflict of interests.

\section{Acknowledgment}

This work has been supported by Medical and Pharmacy School, Mohammed V University, Rabat, Morocco.

\section{References}

[1] W. McClellan, S. L. Aronoff, W. K. Bolton et al., "The prevalence of anemia in patients with chronic kidney disease," Current Medical Research and Opinion, vol. 20, no. 9, pp. 1501-1510, 2004.

[2] C.-Y. Hsu, "Epidemiology of anemia associated with chronic renal insufficiency," Current Opinion in Nephrology and Hypertension, vol. 11, no. 3, pp. 337-341, 2002.

[3] P. A. Marsden, "Treatment of anemia in chronic kidney disease-strategies based on evidence," The New England Journal of Medicine, vol. 361, no. 21, pp. 2089-2090, 2009.

[4] J. Jordan, J. Breckles, V. Leung, M. Hopkins, and M. Battistella, "Conversion from epoetin alfa to darbepoetin alfa: effects on patients' hemoglobin and costs to Canadian dialysis centres," Canadian Journal of Hospital Pharmacy, vol. 65, no. 6, pp. 443449, 2012.

[5] R. W. Evans, B. Rader, and D. L. Manninen, "The quality of life of hemodialysis recipients treated with recombinant human erythropoietin. Cooperative Multicenter EPO Clinical Trial Group," The Journal of the American Medical Association, vol. 263, no. 6, pp. 825-830, 1990.

[6] S. Li, R. N. Foley, and A. J. Collins, "Anemia, hospitalization, and mortality in patients receiving peritoneal dialysis in the United States," Kidney International, vol. 65, no. 5, pp. 1864-1869, 2004.

[7] F. Locatelli, R. L. Pisoni, C. Combe et al., "Anaemia in haemodialysis patients of five European countries: association with morbidity and mortality in the Dialysis Outcomes and Practice Patterns Study (DOPPS)," Nephrology Dialysis Transplantation, vol. 19, no. 1, pp. 121-132, 2004.

[8] H. C. Rayner, R. L. Pisoni, J. Bommer et al., "Mortality and hospitalization in haemodialysis patients in five European countries: results from the Dialysis Outcomes and Practice Patterns
Study (DOPPS)," Nephrology Dialysis Transplantation, vol. 19, no. 1, pp. 108-120, 2004.

[9] "References," Kidney International Supplements, vol. 2, no. 4, pp. 331-335, 2012.

[10] N. W. Levin, S. Fishbane, F. V. Cañedo et al., "Intravenous methoxy polyethylene glycol-epoetin beta for haemoglobin control in patients with chronic kidney disease who are on dialysis: a randomised non-inferiority trial (MAXIMA)," The Lancet, vol. 370, no. 9596, pp. 1415-1421, 2007.

[11] I. C. Macdougall, R. Walker, R. Provenzano et al., "C.E.R.A. Corrects anemia in patients with chronic kidney disease not on dialysis: results of a randomized clinical trial," Clinical Journal of the American Society of Nephrology, vol. 3, no. 2, pp. 337-347, 2008.

[12] F. Dellanna, R. E. Winkler, F. Bozkurt et al., "Dosing strategies for conversion of haemodialysis patients from short-acting erythropoiesis stimulating agents to once-monthly C.E.R.A.: experience from the MIRACEL study," International Journal of Clinical Practice, vol. 65, no. 1, pp. 64-72, 2011.

[13] C. E. Halstenson, M. Macres, S. A. Katz et al., "Comparative pharmacokinetics and pharmacodynamics of epoetin alfa and epoetin beta," Clinical Pharmacology and Therapeutics, vol. 50, no. 6, pp. 702-712, 1991.

[14] H. Schmid, "Cost-effectiveness of continuous erythropoietin receptor activator in anemia," ClinicoEconomics and Outcomes Research, vol. 6, pp. 319-330, 2014.

[15] I. C. Macdougall, R. Robson, S. Opatrna et al., "Pharmacokinetics and pharmacodynamics of intravenous and subcutaneous continuous erythropoietin receptor activator (C.E.R.A.) in patients with chronic kidney disease," Clinical Journal of the American Society of Nephrology, vol. 1, no. 6, pp. 1211-1215, 2006.

[16] SMN, Moroccan Society of Nephrology Guidelines RBMP. ALD 17(Insuffisance Renal Chronique Terminale), SMN, 2011.

[17] P. Gonzalez, E. Gomez, and J. Vargas, "PSY25 Renal Anemia (RA) treatment in Mexican public health care institutions: an evaluation of the costs and consequences," Value in Health, vol. 12, no. 7, pp. A379-A380, 2009.

[18] F. H. C. V. Silva, C. M. D. M. Vianna, and F. V. C. Silva, "PUK3 Cost-effectiveness of anemia treatment in dialysis patients in Brazil," Value in Health, vol. 14, no. 7, p. A570, 2011.

[19] D. Husereau, M. Drummond, S. Petrou et al., "Consolidated health economic evaluation reporting standards (CHEERS) explanation and elaboration: a report of the ISPOR health economic evaluation publication guidelines good reporting practices task force," Value in Health, vol. 16, no. 2, pp. 231-250, 2013.

[20] N. Bezditko, L. Iakovlieva, O. Mishchenko, O. Gerasymova, and O. Kyrychenko, "PUK24 Pharmacoeconomic aspects of use of erythropoietin drugs in patients on hemodialysis in Ukraine," Value in Health, vol. 15, no. 7, p. A459, 2012.

[21] S. Franz, C. Jäger, and T. Gauthier, "Hemoglobin levels and development of ESA dose in hemodialysis patients after conversion to CERA: a multicenter observational study," Swiss Medical Weekly, vol. 139, no. 45-46, supplement 178, p. 8S, 2009.

[22] M. D. Albero Molina, R. López-Menchero Martínez, C. del Pozo Fernández, L. Álvarez Fernández, and L. Sánchez Rodríguez, "Eficiencia de la administración mensual subcutánea de metoxi-polietilenglicol epoetina $\beta$ (Mircera) en pacientes estables en hemodiálisis previamente tratados con eritropoyetinaEficiencia de la administración sc mensual de MIRCERA en pacientes en HD," Diálisis y Trasplante, vol. 34, no. 3, pp. 93100, 2013. 
[23] V. Escudero-Vilaplana, C. Martínez-Nieto, J. M. López-Gómez, A. Vega-Martínez, J. M. Bellón-Cano, and M. Sanjurjo-Sáez, "Erythropoiesis-stimulating agents in anaemia due to chronic kidney disease: a cost-minimization analysis," International Journal of Clinical Pharmacy, vol. 35, no. 3, pp. 463-468, 2013.

[24] N. Duman, A. Uyanik, A. Unsal et al., "Once-monthly continuous erythropoietin receptor activator (CERA) for haemoglobin maintenance in haemodialysis patients with chronic renal anaemia," Clinical Kidney Journal, vol. 7, no. 5, pp. 464-469, 2014.

[25] U. Saueressig, J. T. C. Kwan, E. De Cock, and C. Sapède, "Healthcare resource utilization for anemia management: current practice with erythropoiesis-stimulating agents and the impact of converting to once-monthly C.E.R.A.," Blood Purification, vol. 26, no. 6, pp. 537-546, 2008.

[26] E. De Cock, F. Dellanna, K. Khellaf et al., "Time savings associated with C.E.R.A. once monthly: a time-and-motion study in hemodialysis centers in five European countries," Journal of Medical Economics, vol. 16, no. 5, pp. 648-656, 2013.

[27] W. F. J. Klatko, "Time and motion study of anaemia management with erythropoiesis stimulating agents in haemodialysis units in Poland," Journal of Health Policy and Outcomes Research, vol. 2, no. 1, pp. 126-132, 2013.

[28] N. W. Levin, "Quality of life and hematocrit level," American Journal of Kidney Diseases, vol. 20, no. 1, supplement 1, pp. 1620, 1992.

[29] M. Tonelli, W. C. Winkelmayer, K. K. Jindal, W. F. Owen Jr., and B. J. Manns, "The cost-effectiveness of maintaining higher hemoglobin targets with erythropoietin in hemodialysis patients," Kidney International, vol. 64, no. 1, pp. 295-304, 2003.

[30] F. M. Clement, S. Klarenbach, M. Tonelli, N. Wiebe, B. Hemmelgarn, and B. J. Manns, "An economic evaluation of erythropoiesis-stimulating agents in CKD," American Journal of Kidney Diseases, vol. 56, no. 6, pp. 1050-1061, 2010. 


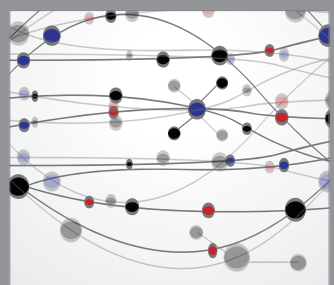

The Scientific World Journal
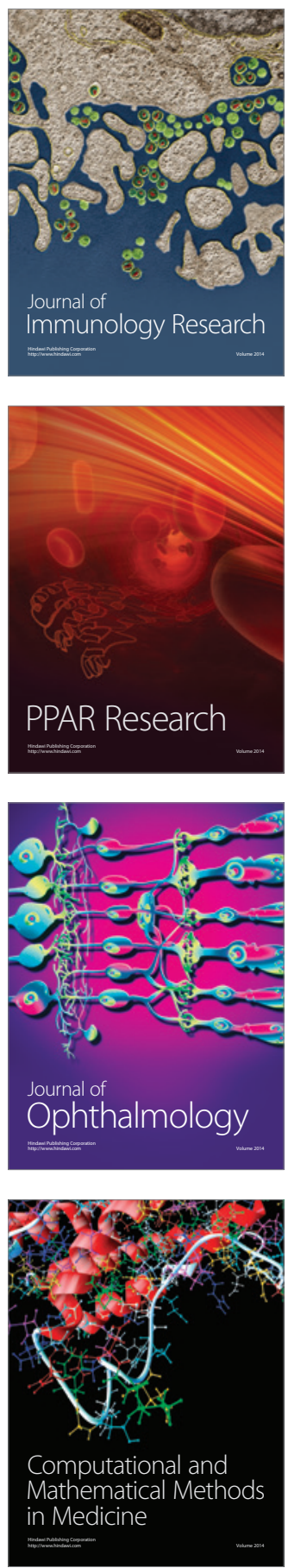

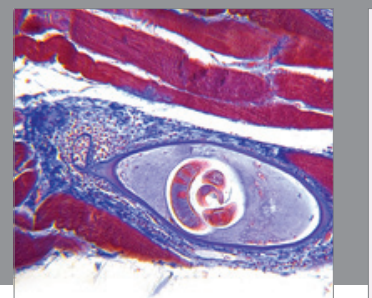

Gastroenterology

Research and Practice
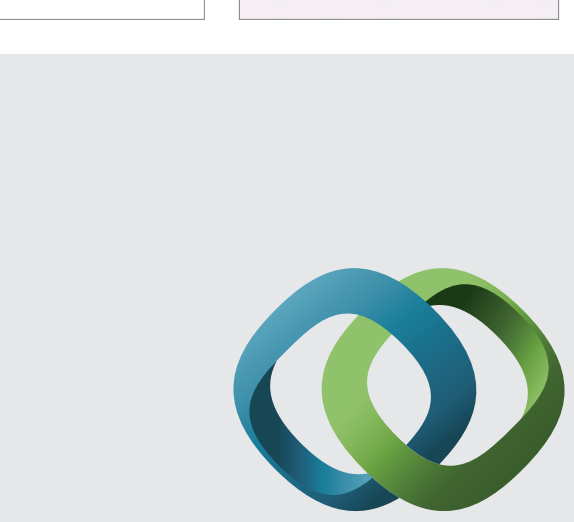

\section{Hindawi}

Submit your manuscripts at

http://www.hindawi.com
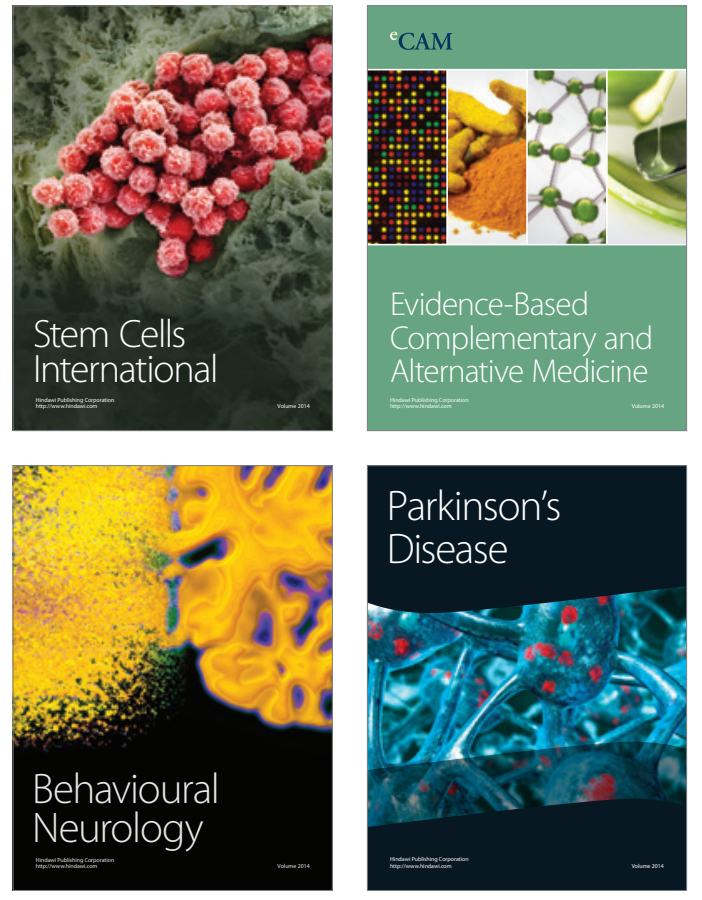
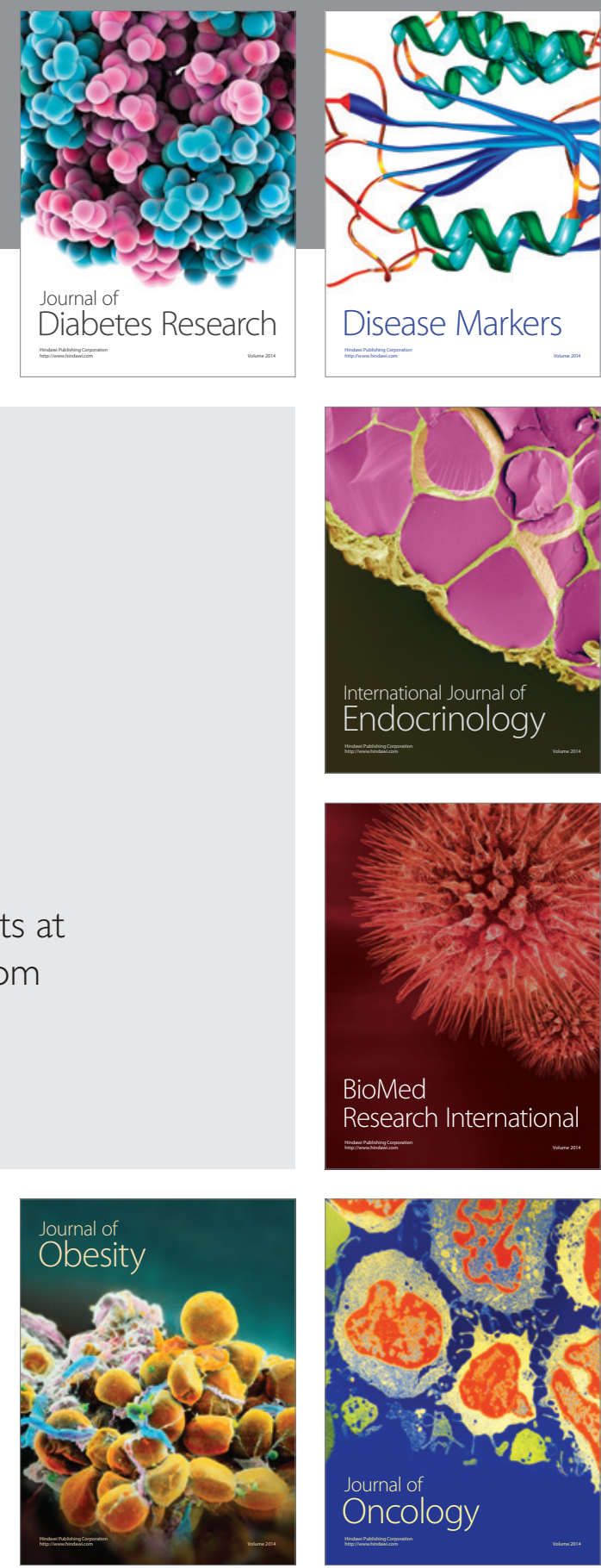

Disease Markers
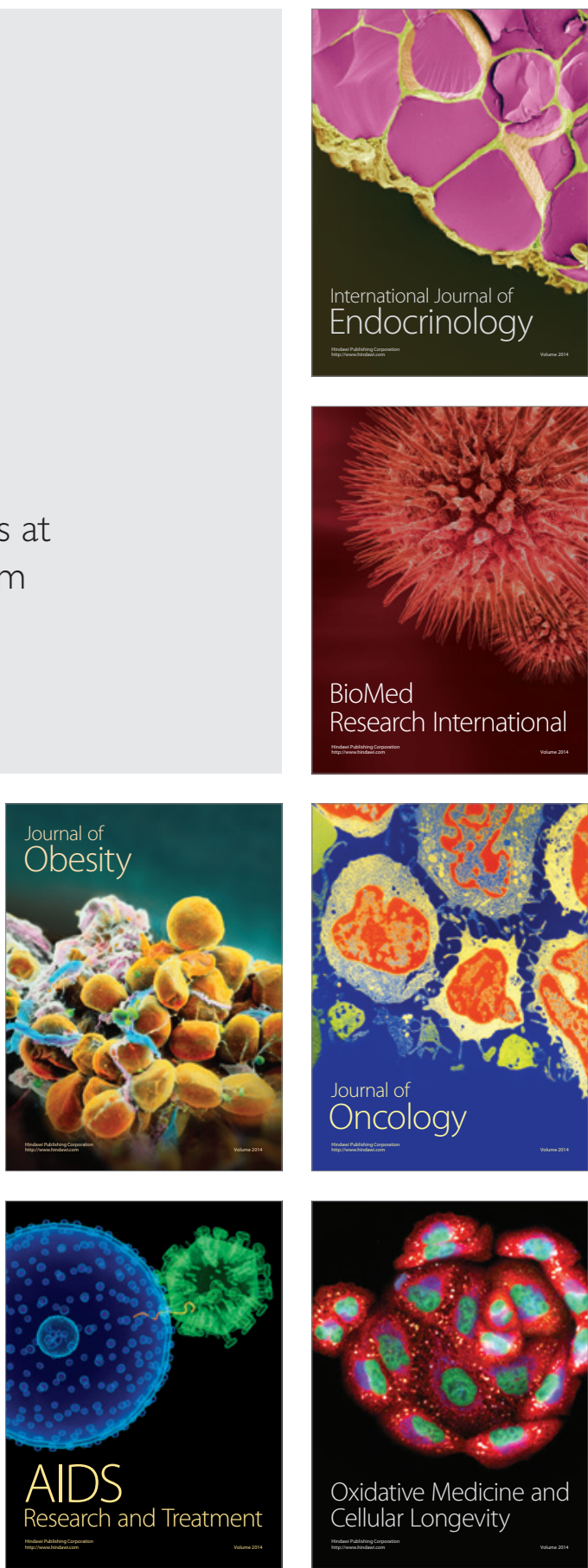